\title{
Knotty Problems during Mitosis: Mechanistic Insight into the Processing of Ultrafine DNA Bridges in Anaphase
}

\author{
Kata Sarlós, ${ }^{1}$ Andreas Biebricher ${ }^{2}$ Erwin J.G. Petermann, ${ }^{2}$ Gijs J.L. Wuite ${ }^{2}$ \\ AND IAN D. HiCKSON ${ }^{1}$ \\ ${ }^{1}$ Center for Chromosome Stability and Center for Healthy Aging, Department of Cellular and Molecular \\ Medicine, University of Copenhagen, 2200 Copenhagen N, Denmark \\ ${ }^{2}$ Department of Physics and Astronomy and LaserLab, Vrije Universiteit Amsterdam, \\ 1081 HVAmsterdam, The Netherlands \\ Correspondence: iandh@sund.ku.dk
}

\begin{abstract}
To survive and proliferate, cells have to faithfully segregate their newly replicated genomic DNA to the two daughter cells. However, the sister chromatids of mitotic chromosomes are frequently interlinked by so-called ultrafine DNA bridges (UFBs) that are visible in the anaphase of mitosis. UFBs can only be detected by the proteins bound to them and not by staining with conventional DNA dyes. These DNA bridges are presumed to represent entangled sister chromatids and hence pose a threat to faithful segregation. A failure to accurately unlink UFB DNA results in chromosome segregation errors and binucleation. This, in turn, compromises genome integrity, which is a hallmark of cancer. UFBs are actively removed during anaphase, and most known UFB-associated proteins are enzymes involved in DNA repair in interphase. However, little is known about the mitotic activities of these enzymes or the exact DNA structures present on UFBs. We focus on the biology of UFBs, with special emphasis on their underlying DNA structure and the decatenation machineries that process UFBs.
\end{abstract}

Visible evidence of mitotic chromosome segregation problems, such as lagging chromatin or bulky (chromatinized) DNA bridges, has long been used as a marker of genomic instability (McClintock 1938, 1942; Gisselsson et al. 2000, 2002; Hoffelder et al. 2004; Thompson and Compton 2011). These structures are generally revealed by staining with DNA dyes such as DAPI. This explains why ultrafine bridges (UFBs) had escaped detection for decades because they cannot be visualized using any of the commonly used dyes (Fig. 1A). Furthermore, because they are dechromatinized, they also cannot be detected by staining for histones. Instead, they were originally revealed through studies of the mitotic localization of DNA processing enzymes, such as the BLM helicase defective in Bloom's syndrome (Chan et al. 2007) or the Polo-like kinase 1 interacting checkpoint helicase (PICH) (Fig. 1A; Baumann et al. 2007). One curious feature of UFBs is the fact that they are generally coated along their length with PICH/BLM even when they are several microns in length in late anaphase.

A number of studies have investigated the mechanisms by which UFBs are generated and resolved (Wang et al. 2008, 2010b; Chan and Hickson 2009; Naim and Rosselli 2009; Nielsen et al. 2015). It is known that UFBs can be induced by exposure to a range of stressors, and that they often arise from defined genomic loci (centromeres, common fragile sites [CFSs], telomeres, and ribosomal DNA [rDNA]). Moreover, interfering with the functions of UFB-binding proteins has serious consequences for mitosis and genome integrity, such as the generation of aneu- ploidy, binucleation, and micronucleus formation (Lukas et al. 2011; Nielsen et al. 2015). In our laboratory, we are developing tools to reconstitute anaphase chromosome segregation in vitro. For this, we are investigating the action of recombinant enzymes present at UFBs by combining ensemble biochemical methods with singlemolecule optical tweezers combined with fluorescence microscopy. Here, we summarize our current knowledge on UFBs based on cellular observations and introduce our in vitro approaches to build a mechanistic model of sister chromatid disjunction.

\section{THE ORIGINS OF UFBS}

Replication causes the newly replicated strands to be interlinked/catenated (Schvartzman and Stasiak 2004; Vos et al. 2011). In parallel to this, the cohesin complex is deposited along the chromosomes to encircle and hold the sister chromatids together (Tanaka et al. 2001; Nasmyth 2011). Most of the DNA catenanes are removed by topoisomerase II $\alpha$ (TopII $\alpha$ ); either during $\mathrm{S}$ phase or during early mitosis when DNA condensation occurs (Hirano 2015). In the prophase of mitosis, most of the cohesin located on chromosome arms (but not at centromeres) is released in a condensation-dependent manner (Hirano 2015). The activities of TopII $\alpha$, condensin I and II, and cohesin are tightly coordinated and give rise to the classical, X-shaped, chromosome structure, where the arms are devoid of both DNA cohesion and DNA cate-

(C) 2017 Sarlós et al. This article is distributed under the terms of the Creative Commons Attribution-NonCommercial License, which permits reuse and redistribution, except for commercial purposes, provided that the original author and source are credited. 
A
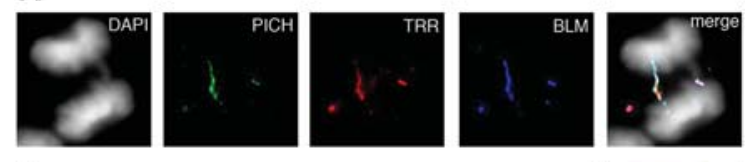

B

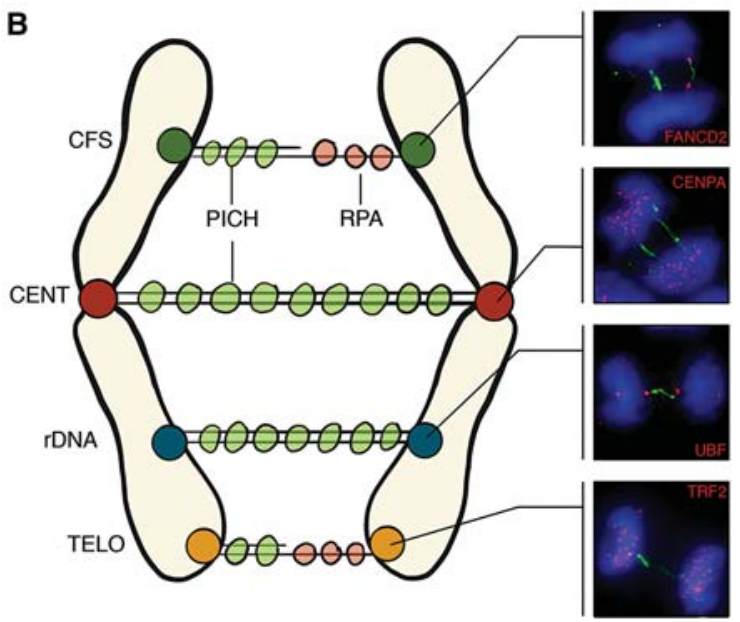

Figure 1. Ultrafine bridges (UFBs) arise in anaphase from various chromosomal loci. (A) Immunofluorescence image of a UFB coated by PICH (green), BLM (blue), and TRR (red). The bulk DNA was stained using DAPI. $(B$, left $)$ Schematic representation of the chromosomal origins of UFBs, marked by surrogate markers at their termini. Examples are shown on the right. From top to bottom: a common fragile state (CFS)-UFB marked by FANCD2, a C-UFB marked by CENPA, an R-UFB marked by UBF, and a T-UFB marked by TRF2. UFBs were visualized using antibodies to $\mathrm{PICH}$ (green).

nanes (Hirano 2015). Interfering with either cohesion or condensation gives rise to UFBs connecting the chromosome arms, suggesting that these processes give directionality to decatenation by TopII $\alpha$ (Baxter and Aragón 2012; Minocherhomji et al. 2015; Piskadlo et al. 2017).

\section{UFBs at Centromeres}

UFBs arising from the centromeres (C-UFBs) can be identified by the presence of centromeric markers such as CENP-A at their termini (Fig. 1B). C-UFBs are by far the most prevalent of all UFBs (Chan et al. 2007, 2009) and exist in every mitosis. Their number is minimized by an active removal process that occurs at anaphase onset (Wang et al. 2008). Importantly, inhibition of TopII $\alpha$ by specific drugs, such as ICRF-193, induces the persistence and number of centromeric UFBs (Baumann et al. 2007; Chan et al. 2007; Wang et al. 2008). Moreover, TopII colocalizes with PICH on ICRF-193-induced UFBs (Nielsen et al. 2015), indicating that TopII $\alpha$ is required for their decatenation. Because centromeric cohesin is protected from release by Sgo1-PP2A (Kitajima et al. 2006), and is only cleaved at anaphase onset by Separase (Uhlmann et al. 2000), it is thought that TopII $\alpha$ only has a brief period in which to decatenate any C-UFBs after cohesin cleavage (Wang et al. 2010b). However, based on their frequency, it is also conceivable that the persistence of centromeric UFBs until anaphase is not simply an unwant- ed side effect of the masking of DNA catenation by cohesin, but rather has a physiological role in maintaining DNA-based sister chromatid "cohesion" until the metaphase-to-anaphase transition.

\section{UFBs at Common Fragile Sites}

CFSs are viewed as an Achilles' heel of the genome. They are frequently deleted or rearranged in cancer cells and can appear as gaps or breaks on mitotic chromosomes following replication perturbation (termed CFS expression) (Glover et al. 1984; Durkin and Glover 2007). CFSs are regions where replication is problematic and delayed (Debatisse et al. 2012). According to recent modeling studies, cells with large genomes enter mitosis with, on average, three underreplicated sites per cell, even in unperturbed growth conditions. This problem is exacerbated by conditions that induce replication stress or by reducing the number of origins (Al Mamun et al. 2016; Moreno et al. 2016).

The Fanconi anemia (FA) DNA repair proteins, FANCD2 and FANCI (Sims et al. 2007; Smogorzewska et al. 2007), associate with CFSs after replication stress and serve as surrogate markers for these loci (Chan et al. 2009; Naim and Rosselli 2009). In contrast to centromeric UFBs, CFS-UFBs (Fig. 1B) rarely appear spontaneously and cannot be induced by inhibiting TopII $\alpha$ (Chan et al. 2009). Rather, CFS-UFBs accumulate after perturbation of DNA replication by the DNA polymerase inhibitor aphidicolin (Chan and Hickson 2009; Naim and Rosselli 2009). This suggests that CFS-UFBs are composed of underreplicated DNA.

\section{UFBs at Telomeres}

The ends of linear eukaryotic chromosomes are organized into well-defined structures called telomeres (Doksani and de Lange 2014; Arnoult and Karlseder 2015). The telomeric DNA is looped back in a DNA structure called a T-loop that prevents the DNA end from being exposed (Griffith et al. 1999; Doksani et al. 2013). T-loops are stabilized by the shelterin complex, which comprises several proteins including telomeric repeat-binding factors 1 and 2 (TRF1 and TRF2) (Palm and de Lange 2008). Telomeres show similarities to CFSs in that replication stress induces the so-called "fragile-telomere" phenotype, where the chromosomes appear to be broken at the very end (Sfeir et al. 2009), indicating that these loci are also inherently difficult to replicate (Martinez and Blasco 2015; Higa et al. 2017). Telomeres give rise to BLM-coated UFBs (TUFBs) (Fig. 1B) following exposure to aphidicolin (Chan and Hickson 2009; Barefield and Karlseder 2012; d'Alcontres et al. 2014). Interfering with the integrity of the shelterin complex via changing the levels of TRF1 or TRF2 also induces telomere fragility (Martinez et al. 2009; Sfeir et al. 2009) and gives rise to T-UFBs (d'Alcontres et al. 2014; Nera et al. 2015). TRF1 was shown to protect against fragility by recruiting BLM to the telomeres (Sfeir et al. 2009), suggesting that BLM facilitates replication (Drosopoulos et al. 2015) or disentangles late-replicating 
structures at these regions (Chan et al. 2009; Barefield and Karlseder 2012). In contrast to CFS-UFBs, inhibition of TopII $\alpha$ by ICRF-193 induces T-UFBs, and TRF1 has been shown to recruit TopII $\alpha$ to telomeres. These findings suggest that at least a subset of T-UFBs are likely be completely replicated, double-stranded DNA (dsDNA) catenanes (d'Alcontres et al. 2014).

\section{UFBs at the rDNA}

$\mathrm{PICH}$ is present at rDNA loci in chicken and human cells in early mitosis (Nielsen et al. 2015). The rDNA loci also occasionally give rise to PICH- and TopII $\alpha$-decorated R-UFBs (Fig. 1B; Nielsen and Hickson 2016). The number of R-UFBs increases following inhibition of TopII $\alpha$ by ICRF-193. This suggests that the structure and decatenation mechanism of R-UFBs are similar to those of CUFBs. The rDNA locus is known to be segregated late during mitosis in yeast (Sullivan et al. 2004; Wang et al. 2004; Clemente-Blanco et al. 2009) and has been shown to be transcriptionally active even in early mitosis in humans (Gebrane-Younes et al. 1997; Sirri et al. 1999; Voit et al. 2015). Because active transcription interferes with condensation, which, in turn, is required for decatenation by TopII $\alpha$ (Lukas et al. 2011; Baxter and Aragón 2012), this would leave cells only a short time window in which to decatenate the rDNA during mitosis, thus potentially explaining the appearance of UFBs from these loci.

\section{UFB RECOGNITION AND PROCESSING MACHINERIES}

\section{PICH}

PICH was first identified as an interacting factor of the mitotic kinase Plk1 (Baumann et al. 2007). PICH is excluded from the nucleus during interphase and is only recruited to chromatin after nuclear envelope breakdown, whereupon it accumulates at centromeric loci. PICH seems to be the main recognition and recruitment factor for UFBs, as several other UFB-processing factors fail to localize to UFBs in the absence of PICH, such as members of the Bloom syndrome complex (Chan et al. 2007) and RIF1 (Hengeveld et al. 2015). This makes it difficult to detect or analyze UFBs in the absence of PICH. PICH was reported to influence chromosome condensation, as chromosome structure is abnormal in the absence of PICH (Leng et al. 2008; Kurasawa and Yu-Lee 2010; Rouzeau et al. 2012; Nielsen et al. 2015). PICH belongs to the SNF2 family of translocases (Singleton et al. 2007) and contains a motor domain typical in this enzyme family (Fig. 2A). Consistent with this, PICH possesses ATP-dependent dsDNA translocase activity (Biebricher et al. 2013). In addition to the SNF2 region, PICH has accessory domains, including the PICH-family domain, and two TPR motifs reported to be involved in protein interactions (Hengeveld et al. 2015; Pitchai et al. 2017). PICH appears to have a high affinity for stretched dsDNA, which is consistent with the idea that UFBs must be under considerable tension created by the mitotic spindle (Baumann

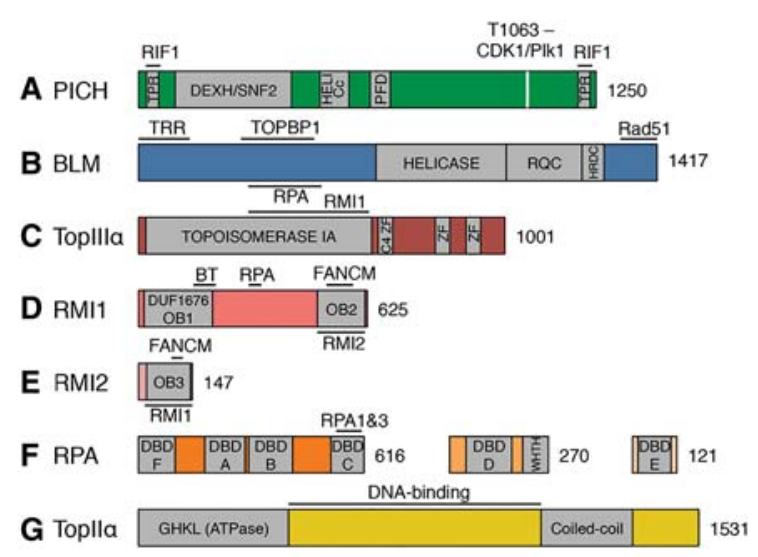

Figure 2. Domain structure of UFB-associated proteins and their interactions. (A) PICH: The amino- and carboxy-terminal TPR, SNF2, HeliCc, PICH-family domains are indicated. PICH interacts with RIF1 via the TPRs. The CDK1 phosphorylation site required for interaction with Plk1 is indicated. $(B)$ BLM: The RecQ core comprised of the helicase, the RecQ carboxy-terminal, and the HRDC domains, as well as some known interaction sites, are indicated. $(C)$ TopIII $\alpha$ : The conserved topoisomerase IA domain, zinc fingers, and putative interaction region with RMI1 are indicated - the BLM-interaction site is not known. $(D)$ RMI1 and $(E)$ RMI2: The OB-folds, sites for complex formation, and interaction sites for BLM/TopIII $\alpha$, RPA and FANCM are indicated. $(F)$ RPA is composed of three subunits. The six DNA-binding sites, the winged-helix-turn-helix domain, and complex-formation sites are indicated. $(G)$ TopII $\alpha$ : The conserved ATPase domain, DNA-binding region, and coiled-coil required for dimerization are indicated. The locations of interacting sites are not known.

et al. 2007; Biebricher et al. 2013). Indeed, this property of PICH may be the main mechanism for how cells normally sense UFBs. Somewhat surprisingly, a PICH mutant lacking ATPase activity does not increase the number of UFBs, although it does prolong their persistence (Nielsen et al. 2015) and also increases the number of chromatin bridges, indicating that UFBs and chromatin bridges have different origins (Kaulich et al. 2012). It should be noted, however, that the ATPase-dead PICH shows altered localization on metaphase chromosomes (Kaulich et al. 2012).

\section{The Bloom Syndrome Protein Complex}

BLM is the helicase mutated in Bloom syndrome (BS), a severe autosomal hereditary disorder causing genetic instability and cancer (Ellis et al. 1995; German et al. 2007; Cunniff et al. 2017). BLM belongs to the RecQ family, a group of evolutionary conserved genome caretaking enzymes (Chu and Hickson 2009; Croteau et al. 2014), and comprises a helicase core, flanked by long amino- and carboxy-terminal regions responsible for protein-protein interactions (Fig. 2B; Wu et al. 2000, 2001; Meetei et al. 2003; Doherty et al. 2005; Wang et al. 2013; Blackford et al. 2015). BLM efficiently unwinds various DNA structures such as replication forks (Karow et al. 1997), fourway junctions (Karow et al. 2000), D-loops (Bachrati et al. 2006), or G4 quadruplexes (Sun et al. 1998).

BLM directly interacts with topoisomerase III $\alpha$ (TopIII $\alpha$ ) (Wallis et al. 1989; Goulaouic et al. 1999; Wu et al. 
2000), a Type 1A topoisomerase that can catalyze only single-stranded DNA (ssDNA) strand passage (Wallis et al. 1989; Vos et al. 2011). TopIII $\alpha$ is composed of a conserved type $1 \mathrm{~A}$ topoisomerase domain and multiple zinc-finger motifs that are located in the predominantly disordered carboxyl terminus (Fig. 2C). BLM and TopIII $\alpha$ together disentangle complex DNA structures, such as the double Holliday junction (dHJ) (Wu and Hickson 2003), a key intermediate in homologous recombination-based DNA repair (Yin et al. 2005; Bizard and Hickson 2014). In higher eukaryotes, the complex is augmented by the RecQ-mediated instability (RMI) 1 (Meetei et al. 2003; Yin et al. 2005) and 2 (Singh et al. 2008; Xu et al. 2008) proteins, forming direct physical interactions with both BLM (Raynard et al. 2006) and TopIII $\alpha$ (Raynard et al. 2006; Bocquet et al. 2014). RMI1 and RMI2 are both OBfold-containing proteins (Fig. 2D,E), with no inherent enzymatic activity. However, importantly, RMI1 stimulates the dHJ dissolution by BLM and TopIII $\alpha$ (Raynard et al. 2006; Wu et al. 2006), whereas RMI2 has a very modest effect on this activity (Singh et al. 2008; Xu et al. 2008). RMI1 and RMI2 form a complex (Hoadley et al. 2010; Wang et al. 2010a) that is required to stabilize TopIII $\alpha$. As a result, they form a constitutive heterotrimer (termed the "TRR complex") in vivo.

BLM has been used as a key marker of UFBs in many studies (Chan and Hickson 2009; Chan et al. 2009; Vinciguerra et al. 2010; Ke et al. 2011; Lukas et al. 2011; Barefield and Karlseder 2012; Broderick et al. 2015; Hengeveld et al. 2015). Considering that the BTRR complex has evolved to disentangle complex DNA structures, it is conceivable that this complex is responsible for UFB processing. This is supported by the observation that BS cells, and cells depleted of BLM by short interfering RNAs (siRNAs), display increased levels of all types of UFBs, and that these UFBs often persist into late telophase in these cells (Chan et al. 2007; Barefield and Karlseder 2012).

The recruitment of the BTRR complex to UFBs depends on PICH, and they always seem to coat the same stretch of DNA (Chan et al. 2007). This localization is somewhat curious, considering the fact that PICH binds exclusively to dsDNA (Biebricher et al. 2013), whereas the BTRR prefers ssDNA. The observation that BLM interacts with the carboxyl terminus of PICH suggests that PICH recruits the BTRR complex via direct interactions (Ke et al. 2011).

\section{RPA}

Replication protein A is an essential ssDNA binding protein required for most DNA transactions (Wold 1997; Zou et al. 2006). It is composed of three subunits (Fig. 2F) and interacts with the BTRR complex, both functionally and directly via BLM (Brosh et al. 2000; Meetei et al. 2003; Doherty et al. 2005) and RMI1 (Xue et al. 2013). RPA is detectable on a subset of UFBs in anaphase in response to DNA replication stress induced by aphidicolin (Chan and Hickson 2009; Burrell et al. 2013), indicating the presence of ssDNA on some CFS-UFBs (Chan et al. 2009). BLM and RPA show a nonoverlapping pattern of localization to UFBs, which suggests that the recruitment of BLM to PICH-coated double-stranded UFBs is independent of its interaction with RPA (Porter and Farr 2004; Chan and Hickson 2009). Interestingly, the appearance of RPA-coated UFBs has been shown to be BLM-dependent, implicating BLM in unwinding some structure to create ssDNA (Hengeveld et al. 2015).

\section{Topoisomerase II $\alpha$}

TopII $\alpha$ is the enzyme responsible for the majority of decatenation of chromosomes in early mitosis (Porter and Farr 2004). TopII $\alpha$ is a homodimeric Type IIA topoisomerase (Fig. $2 \mathrm{G}$ ) that catalyzes the passage of one piece of dsDNA through another in an ATP-dependent manner (Schoeffler and Berger 2008). Even though TopII $\alpha$ does not seem to directly interact with $\mathrm{PICH}$, it is present at PICH-coated UFBs, and PICH is able to stimulate decatenation by TopII $\alpha$ in vivo and in vitro (Nielsen et al. 2015). It has been suggested that TopII $\alpha$ is recruited to a subset of UFBs via direct interaction with TOPBP1 (Broderick et al. 2015).

\section{Other UFB-Associated Proteins}

RIF1, TOPBP1, and FANCM were also reported to coat some UFBs (Meetei et al. 2003; Deans and West 2009; Xu et al. 2010; Hoadley et al. 2012; Wang et al. 2013; Blackford et al. 2015). We will not discuss these factors further here, but instead refer readers to relevant publications (German et al. 2007; Vinciguerra et al. 2010; Broderick et al. 2015; Hengeveld et al. 2015; Pedersen et al. 2015).

\section{MODELING UFBs IN A TEST TUBE}

Mechanistic insight into the mode of UFB resolution is lacking. To gain a comprehensive understanding of this process, our laboratory is using interdisciplinary approaches to reconstitute mitotic DNA decatenation in vitro. To achieve this, we combine ensemble biochemistry on model DNA substrates, with single-molecule optical tweezers coupled to fluorescence microscopy (Heller et al. 2014).

\section{Modeling UFBs Using Ensemble Biochemistry}

CFS and telomeres are both difficult-to-replicate regions, and both CFS-UFBs and T-UFBs are induced by replication stress (Chan and Hickson 2009; Barefield and Karlseder 2012). Therefore, it is thought that these UFBs are composed of underreplicated DNA (Fig. 3A). To study such a UFB in vitro, we created a substrate termed a "late replication intermediate" (LRI), which comprises two interlinked DNA circles mimicking two converging replication forks (A Sarlós, A Biebricher, and AH Bizard, unpubl.). We hypothesized that an LRI would be an ideal substrate for the BTRR complex. Indeed, a similar substrate was shown previously to be processed by the Escherichia coli homologs of the BTRR complex (Suski and Marians 2008). 
A
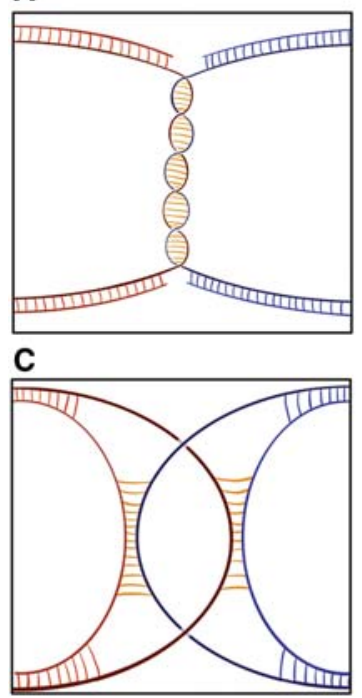

B

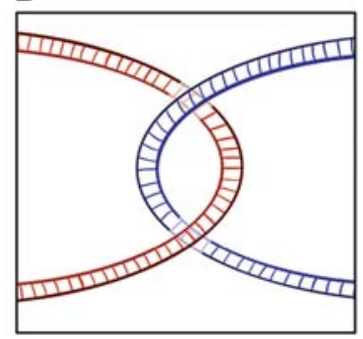

D

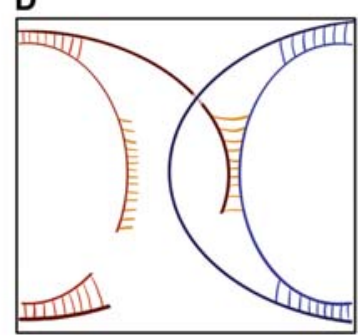

Figure 3. Hypothetical DNA structures that could be present at UFBs. $(A)$ A late replication intermediate, $(B)$ a complete doublestranded catenane, $(C)$ a double Holliday junction, and $(D)$ a Dloop.

As discussed above, TopII $\alpha$ inhibition dramatically increases the number of C-UFBs (Chan et al. 2009). RUFBs are also induced by ICRF-193 and are thought to arise because of the late condensation of the rDNA locus hindering decatenation (Nielsen and Hickson 2016). Con-

sidering that TopII $\alpha$ is a dsDNA-specific enzyme, this implies that the majority of C-UFBs and R-UFBs are completely double-stranded catenanes (Fig. 3B). To model this, we used a single-catenane substrate comprised of two interlinked dsDNA circles (Stark et al. 1989; Nielsen et al. 2015). Considering that the BTRR complex prefers ss/dsDNA junctions, it is not clear what the function of BTRR might be on C-UFBs (Chan et al. 2007). Because studies involving the yeast and $E$. coli homologs of BTRR reported some dsDNA catenation activity (Harmon et al. 2003; Cejka et al. 2012), it is conceivable that the BTRR can decatenate ds-UFBs if TopII $\alpha$ is prohibited.

Most of the enzymes implicated in UFB processing are also involved in DNA repair. Therefore, it cannot be excluded that some UFBs are composed of HR intermediates, such as a dHJ or a D-loop (Fig. 3C,D). Such DNA structures would be expected to be "dissolved" efficiently by the BTRR complex (Wu and Hickson 2003; Bachrati et al. 2006).

\section{Modeling of UFBs in Single-Molecule Experiments}

Single-molecule techniques can provide information on enzymatic mechanisms that would be inaccessible by ensemble methods because of the averaging of the activity of thousands of molecules at the same time (Neuman and Nagy 2008). One of the most widely used singlemolecule techniques is optical tweezers (Fig. 4A). Using optical tweezers, a single piece of biotinylated DNA can

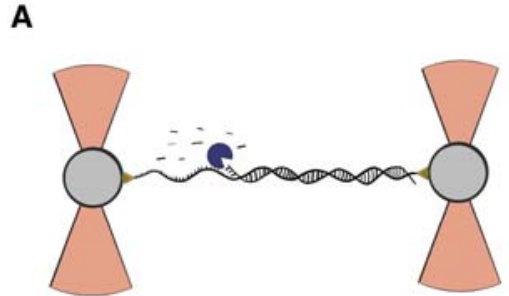

C

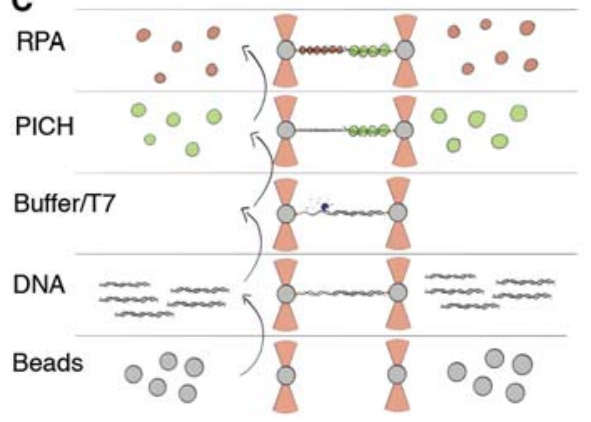

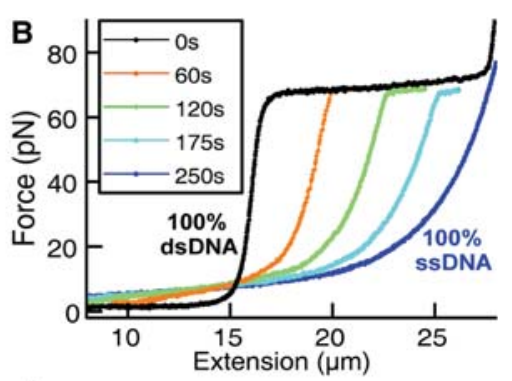

D

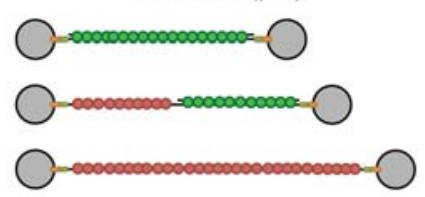

E

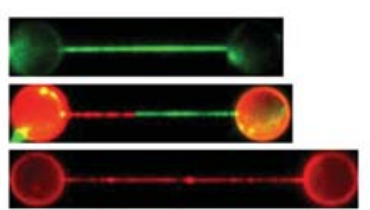

Figure 4. Scheme of optical tweezers experiments. (A) A biotin-labeled dsDNA molecule stretched between two streptavidin-coated beads (gray) entrapped by laser beams (orange). The exonuclease activity of T7 DNA polymerase (blue) is shown creating ssDNA. (B) A series of DNA force-extension curves, ranging from full-length dsDNA (black) to full-length ssDNA (blue). The orange, green, and cyan curves represent increasing incubation time with T7 DNA polymerase (as shown in the inset), which results in increasing lengths of ssDNA tracts. $(C)$ Outline of an experimental scheme for use of a flow cell with five channels. First beads are trapped, and then a dsDNA molecule is captured; this can subsequently be converted into an ss/dsDNA hybrid. This is followed by incubation with fluorescently labeled proteins, such as GFP-PICH (green) or RFP-RPA (red). $(D, E)$ Schemes $(D)$ and fluorescence snapshots $(E)$ of a GFP-PICH-coated dsDNA molecule, a RFP-RPA/GFP-PICH-coated ss/dsDNA hybrid molecule, and a RFP-RPA-coated ssDNA stretch. Note that the extension of the DNA molecule is increasing by the introduction of ssDNA, which has a longer contour length than dsDNA. 
be tethered between streptavidin-coated polystyrene microspheres and manipulated in the flow cell of a fluorescence microscope (Heller et al. 2014). The effect of tension applied to a model UFB can thus be addressed, and fluorescently tagged proteins can be directly visualized on the stretched DNA.

The simplest UFB model one can imagine is a piece of dsDNA stretched between two beads. Indeed, we have showed using this approach that PICH is a DNA "tension sensor" that binds to stretched dsDNA with high affinity and translocates along the DNA in an ATP-dependent manner (Biebricher et al. 2013). However, as discussed above, presumably not all UFBs are completely doublestranded, and there are also multiple players involved in their processing. It is possible to generate a section of ssDNA with optical tweezers by stretching a dsDNA molecule to forces beyond $65-70 \mathrm{pN}$, which induces base pair melting. Occasionally, in the presence of a nick (a break in one of the strands), the melted strand dissociates, yielding a permanent stretch of ssDNA (Candelli et al. 2013). A more controlled way to generate a ssDNA/dsDNA hybrid is by using the exonuclease activity of the T7 DNA polymerase induced by putting the DNA under tension (Wuite et al. 2000; Hoekstra et al. 2017). Because reducing the tension can stop the exonuclease activity, a single DNA molecule can be generated containing the desired amount of ssDNA (Fig. 4B). The use of a multichannel flow cell system allows combination of different channels, containing various buffers and proteins, and the same piece of DNA can be freely manipulated between them with minimal contamination (Fig. 4C; Heller et al. 2014). UFBs can be modeled by incubating the DNA with different fluorescently labeled UFB-binding factors. Examples of a full-length dsDNA, a mixed ss/dsDNA, and a full-length ssDNA molecule coated with either GFP-PICH and/or strawberry RPA are shown in Figure 4D,E. By using other fluorescently labeled UFB-factors, such as BLM, the hierarchical recruitment of UFB-processing enzymes to PICH- versus RPA-coated UFBs could in principle be analyzed.

As described above, UFBs are likely to comprise interlinked dsDNA catenanes, and therefore a single piece of DNA, even if it is a mixture of ss/dsDNA, is not suitable for addressing details of the decatenation process. Braiding two DNA molecules together using quadruple-trap optical tweezers would provide a way to achieve this (Brouwer et al. 2017). Furthermore, implementation of confocal microscopy, or recent advances such as super-resolution imaging, allows the monitoring of real-time dynamics of individual molecules on model UFBs even in high fluorescent protein background (Heller et al. 2013).

\section{WHAT HAPPENS IF THE CONVENTIONAL DNA DECATENATION PATHWAYS FAIL?}

Cells seem to wait until the last moment to achieve correct segregation and can delay the completion of anaphase/telophase to accomplish this. This is reflected in BS cells, where UFBs persist even in very late telophase, spanning several microns between the two forming daughter cells (Chan et al. 2007). However, in some cases, when TopII $\alpha$ or the BTRR complex is overwhelmed or inhibited, endonucleases might ensure that the DNA be cleaved in an apparently less controlled way, but nevertheless in a manner that avoids rupture of the bridge during abscission (Sarbajna et al. 2014; Maciejowski et al. 2015). Unresolved UFBs can also cause cytokinesis delay or the abandonment of cytokinesis, resulting in binucleation (Vinciguerra et al. 2010; Wang et al. 2010b; Germann et al. 2014; Nielsen et al. 2015).

Oncogene-induced replication stress generates UFBs, which is exacerbated in cancer cells (Burrell et al. 2013). Unresolved CFS-UFBs induced by replication stress can lead to the formation of 53BP1 nuclear bodies in the next $\mathrm{G}_{1}$ phase (Harrigan et al. 2011; Lukas et al. 2011). Interfering with CFS processing mechanisms also induces chromosome missegregation and aneuploidy (Naim and Rosselli 2009; Ying et al. 2013; Minocherhomji et al. 2015). In line with this, depletion of UFB-associated enzymes such as BLM also generates micronuclei (Rosin and German 1985). Micronuclei are a source of chromothripsis, one of the drivers of genomic rearrangements in cancer (Crasta et al. 2012; Zhang et al. 2015).

\section{CONCLUSION}

Since their discovery 10 years ago, UFBs have become one of the key markers of genomic instability. It has also become more obvious that cells have to cope with DNA entanglements during mitosis much more frequently than was thought previously. As UFBs arise systematically from specific loci (centromeres, fragile sites, telomeres, and rDNA), specialized recognition and processing machineries have evolved to maintain the stability of these important regions. The significance of understanding fundamental mechanisms ensuring correct chromosome segregation cannot be overestimated, especially in the context of cancer. All essential cellular processes can only be understood properly by combining in vivo observations with in vitro model building studies. In the field of mitosis, comprehensive studies where key aspects of mitosis are reconstituted are still in a very early phase. Clearly, interdisciplinary studies are required to construct a mechanistic model of chromosome segregation. In this review, we have highlighted how the combination of biochemical and singlemolecule modeling of DNA structures is a useful tool to study UFBs, impediments of faithful segregation.

\section{ACKNOWLEDGMENTS}

We thank all members of the Hickson laboratory for helpful discussions and Hocine W. Mankouri and Anna H. Bizard for valuable comments on the manuscript. Work in the authors' laboratory is supported by the Danish National Research Foundation (DNRF115), the European Research Council, the Nordea Foundation, and a Future and Emerging Technologies grant from the European Union H2020 fund. 


\section{REFERENCES}

Al Mamun M, Albergante L, Moreno A, Carrington JT, Blow JJ, Newman TJ. 2016. Inevitability and containment of replication errors for eukaryotic genome lengths spanning megabase to gigabase. Proc Natl Acad Sci 113: E5765-E5774.

Arnoult N, Karlseder J. 2015. Complex interactions between the DNA-damage response and mammalian telomeres. Nat Struct Mol Biol 22: 859-866.

Bachrati CZ, Borts RH, Hickson ID. 2006. Mobile D-loops are a preferred substrate for the Bloom's syndrome helicase. Nucleic Acids Res 34: 2269-2279.

Barefield C, Karlseder J. 2012. The BLM helicase contributes to telomere maintenance through processing of late-replicating intermediate structures. Nucleic Acids Res 40: 7358-7367.

Baumann C, Körner R, Hofmann K, Nigg EA. 2007. PICH, a centromere-associated SNF2 family ATPase, is regulated by Plk1 and required for the spindle checkpoint. Cell 128: 101114

Baxter J, Aragón L. 2012. A model for chromosome condensation based on the interplay between condensin and topoisomerase II. Trends Genet 28: 110-117.

Biebricher A, Hirano S, Enzlin JH, Wiechens N, Streicher WW, Huttner D, Wang LHC, Nigg EA, Owen-Hughes T, Liu Y, et al. 2013. PICH: A DNA translocase specially adapted for processing anaphase bridge DNA. Mol Cell 51: 691-701.

Bizard AH, Hickson ID. 2014. The dissolution of double Holliday junctions. CSH Perspect Biol 6: a016477.

Blackford AN, Nieminuszczy J, Schwab RA, Galanty Y, Jackson SP, Niedzwiedz W. 2015. TopBP1 interacts with BLM to maintain genome stability but is dispensable for preventing BLM degradation. Mol Cell 57: 1133-1141.

Bocquet N, Bizard AH, Abdulrahman W, Larsen NB, Faty M, Cavadini S, Bunker RD, Kowalczykowski SC, Cejka P, Hickson ID, et al. 2014. Structural and mechanistic insight into Holliday-junction dissolution by Topoisomerase III $\alpha$ and RMI1. Nat Struct Mol Biol 21: 261-268.

Broderick R, Nieminuszczy J, Blackford AN, Winczura A, Niedzwiedz W. 2015. TOPBP1 recruits TOP2A to ultra-fine anaphase bridges to aid in their resolution. Nat Commun 6: 6572 .

Brosh RM, Li JL, Kenny MK, Karow JK, Cooper MP, Kureekattil RP, Hickson ID, Bohr VA. 2000. Replication protein A physically interacts with the Bloom's syndrome protein and stimulates its helicase activity. J Biol Chem 275: 23500 23508

Brouwer I, King GA, Heller I, Biebricher AS, Peterman EJG, Wuite GJL. 2017. Probing DNA-DNA interactions with a combination of quadruple-trap optical tweezers and microfluidics. Methods Mol Biol 1486: 275-293.

Burrell RA, McClelland SE, Endesfelder D, Groth P, Weller MC, Shaikh N, Domingo E, Kanu N, Dewhurst SM, Gronroos E, et al. 2013. Replication stress links structural and numerical cancer chromosomal instability. Nature 494: 492-496. Erratum 500: 490.

Candelli A, Hoekstra TP, Farge G, Gross P, Peterman EJ, Wuite GJ. 2013. A toolbox for generating single-stranded DNA in optical tweezers experiments. Biopolymers 99: 611-620.

Cejka P, Plank JL, Dombrowski CC, Kowalczykowski SC. 2012. Decatenation of DNA by the $S$. cerevisiae Sgs1-Top3-Rmil and RPA complex: A mechanism for disentangling chromosomes. Mol Cell 47: 886-896.

Chan KL, Hickson ID. 2009. On the origins of ultra-fine anaphase bridges. Cell Cycle 8: 3065-3066.

Chan KL, North PS, Hickson ID. 2007. BLM is required for faithful chromosome segregation and its localization defines a class of ultrafine anaphase bridges. EMBO J 26: 3397-3409.

Chan KL, Palmai-Pallag T, Ying S, Hickson ID. 2009. Replication stress induces sister-chromatid bridging at fragile site loci in mitosis. Nat Cell Biol 11: 753-760.

Chu WK, Hickson ID. 2009. RecQ helicases: Multifunctional genome caretakers. Nat Rev Cancer 9: 644-654.

Clemente-Blanco A, Mayan-Santos M, Schneider DA, Machin F, Jarmuz A, Tschochner H, Aragon L. 2009. Cdc14 inhibits transcription by RNA polymerase I during anaphase. Nature 458: 219-222.

Crasta K, Ganem NJ, Dagher R, Lantermann AB, Ivanova EV, Pan YF, Nezi L, Protopopov A, Chowdhury D, Pellman D. 2012. DNA breaks and chromosome pulverization from errors in mitosis. Nature 482: 53-58.

Croteau DL, Popuri V, Opresko PL, Bohr VA. 2014. Human RecQ helicases in DNA repair, recombination, and replication. Annu Rev Biochem 83: 519-552.

Cunniff C, Bassetti JA, Ellis NA. 2017. Bloom's syndrome: Clinical spectrum, molecular pathogenesis, and cancer predisposition. Mol Syndromol 8: 4-23.

d'Alcontres MS, Palacios JA, Mejias D, Blasco MA. 2014. TopoII $\alpha$ prevents telomere fragility and formation of ultra thin DNA bridges during mitosis through TRF1-dependent binding to telomeres. Cell Cycle 13: 1463-1481.

Deans AJ, West SC. 2009. FANCM connects the genome instability disorders Bloom's Syndrome and Fanconi Anemia. Mol Cell 36: 943-953.

Debatisse M, Le Tallec B, Letessier A, Dutrillaux B, Brison O. 2012. Common fragile sites: Mechanisms of instability revisited. Trends Genet 28: 22-32.

Doherty KM, Sommers JA, Gray MD, Lee JW, von Kobbe C, Thoma NH, Kureekattil RP, Kenny MK, Brosh RM. 2005. Physical and functional mapping of the replication protein $\mathrm{A}$ interaction domain of the Werner and Bloom syndrome helicases. J Biol Chem 280: 29494-29505.

Doksani Y, de Lange T. 2014. The role of double-strand break repair pathways at functional and dysfunctional telomeres. Cold Spring Harb Perspect Biol 6: a016576.

Doksani Y, Wu JY, de Lange T, Zhuang XW. 2013. Super-resolution fluorescence imaging of telomeres reveals TRF2-dependent T-loop formation. Cell 155: 345-356.

Drosopoulos WC, Kosiyatrakul ST, Schildkraut CL. 2015. BLM helicase facilitates telomere replication during leading strand synthesis of telomeres. J Cell Biol 210: 191-208.

Durkin SG, Glover TW. 2007. Chromosome fragile sites. Annu Rev Genet 41: 169-192.

Ellis NA, Lennon DJ, Proytcheva M, Alhadeff B, Henderson EE, German J. 1995. Somatic intragenic recombination within the mutated locus BLM can correct the high sister-chromatid exchange phenotype of Bloom syndrome cells. Am J Hum Genet 57: 1019-1027.

Gebrane-Younes J, Fomproix N, Hernandez-Verdun D. 1997. When rDNA transcription is arrested during mitosis, UBF is still associated with non-condensed rDNA. J Cell Sci 110 (P 19): 2429-2440.

German J, Sanz MM, Ciocci S, Ye TZ, Ellis NA. 2007. Syndrome-causing mutations of the $B L M$ gene in persons in the Bloom's Syndrome Registry. Hum Mutat 28: 743-753.

Germann SM, Schramke V, Pedersen RT, Gallina I, Eckert-Boulet N, Oestergaard VH, Lisby M. 2014. TopBP1/Dpb11 binds DNA anaphase bridges to prevent genome instability. $J$ Cell Biol 204: 45-59.

Gisselsson D, Pettersson L, Hoglund M, Heidenblad M, Gorunova L, Wiegant J, Mertens F, Dal Cin P, Mitelman F, Mandahl N. 2000. Chromosomal breakage-fusion-bridge events cause genetic intratumor heterogeneity. Proc Natl Acad Sci 97: $5357-5362$

Gisselsson D, Jonson T, Yu C, Martins C, Mandahl N, Wiegant J, Jin Y, Mertens F, Jin C. 2002. Centrosomal abnormalities, multipolar mitoses, and chromosomal instability in head and neck tumours with dysfunctional telomeres. BrJCancer 37: 202-207.

Glover TW, Berger C, Coyle J, Echo B. 1984. DNA polymerase $\alpha$ inhibition by aphidicolin induces gaps and breaks at common fragile sites in human chromosomes. Hum Genet 67: $136-142$.

Goulaouic H, Roulon T, Flamand O, Grondard L, Lavelle F, Riou JF. 1999. Purification and characterization of human DNA topoisomerase III $\alpha$. Nucleic Acids Res 27: 2443-2450.

Griffith JD, Comeau L, Rosenfield S, Stansel RM, Bianchi A, Moss H, de Lange T. 1999. Mammalian telomeres end in a large duplex loop. Cell 97: 503-514. 
Harmon FG, Brockman JP, Kowalczykowski SC. 2003. RecQ helicase stimulates both DNA catenation and changes in DNA topology by topoisomerase III. J Biol Chem 278: 42668-42678.

Harrigan JA, Belotserkovskaya R, Coates J, Dimitrova DS, Polo SE, Bradshaw CR, Fraser P, Jackson SP. 2011. Replication stress induces 53BP1-containing OPT domains in G1 cells. $J$ Cell Biol 193: 97-108.

Heller I, Sitters G, Broekmans OD, Farge G, Menges C, Wende W, Hell SW, Peterman EJG, Wuite GJL. 2013. STED nanoscopy combined with optical tweezers reveals protein dynamics on densely covered DNA. Nature Methods 10: 910-916.

Heller I, Hoekstra TP, King GA, Peterman EJ, Wuite GJ. 2014. Optical tweezers analysis of DNA-protein complexes. Chem Rev 114: 3087-3119.

Hengeveld RC, de Boer HR, Schoonen PM, de Vries EG, Lens SM, van Vugt MA. 2015. Rif1 is required for resolution of ultrafine DNA bridges in anaphase to ensure genomic stability. Dev Cell 34: 466-474.

Higa M, Fujita M, Yoshida K. 2017. DNA replication origins and fork progression at mammalian telomeres. Genes (Basel) 8: E112.

Hirano T. 2015. Chromosome dynamics during mitosis. Cold Spring Harb Perspect Biol 7: a015792.

Hoadley KA, Xu DY, Xue YT, Satyshur KA, Wang WD, Keck JL. 2010. Structure and cellular roles of the RMI core complex from the bloom syndrome dissolvasome. Structure 18: 1149-1158.

Hoadley KA, Xue YT, Ling C, Takata M, Wang WD, Keck JL. 2012. Defining the molecular interface that connects the Fanconi anemia protein FANCM to the Bloom syndrome dissolvasome. Proc Natl Acad Sci 109: 4437-4442.

Hoekstra TP, Depken M, Lin SN, Cabanas-Danés J, Gross P, Dame RT, Peterman EJ, Wuite GJ. 2017. Switching between exonucleolysis and replication by T7 DNA polymerase ensures high fidelity. Biophys $J$ 112: 575-583.

Hoffelder DR, Luo L, Burke NA, Watkins SC, Gollin SM, Saunders WS. 2004. Resolution of anaphase bridges in cancer cells. Chromosoma 112: 389-397.

Karow JK, Chakraverty RK, Hickson ID. 1997. The Bloom's syndrome gene product is a $3^{\prime}-5^{\prime}$ DNA helicase. $J$ Biol Chem 272: 30611-30614.

Karow JK, Constantinou A, Li JL, West SC, Hickson ID. 2000. The Bloom's syndrome gene product promotes branch migration of Holliday junctions. Proc Natl Acad Sci 97: 6504-6508.

Kaulich M, Cubizolles F, Nigg EA. 2012. On the regulation, function, and localization of the DNA-dependent ATPase PICH. Chromosoma 121: 395-408.

Ke Y, Huh JW, Warrington R, Li B, Wu N, Leng M, Zhang J, Ball HL, Li B, Yu H. 2011. PICH and BLM limit histone association with anaphase centromeric DNA threads and promote their resolution. EMBO J 30: 3309-3321.

Kitajima TS, Sakuno T, Ishiguro K, Iemura S, Natsume T, Kawashima SA, Watanabe Y. 2006. Shugoshin collaborates with protein phosphatase 2A to protect cohesin. Nature 441: 46-52.

Kurasawa Y, Yu-Lee LY. 2010. PICH and cotargeted Plk1 coordinately maintain prometaphase chromosome arm architecture. Mol Biol Cell 21: 1188-1199.

Leng M, Besusso D, Jung SY, Wang Y, Qin J. 2008. Targeting Plk1 to chromosome arms and regulating chromosome compaction by the PICH ATPase. Cell Cycle 7: 1480-1489.

Lukas C, Savic V, Bekker-Jensen S, Doil C, Neumann B, Pedersen RS, Grofte M, Chan KL, Hickson ID, Bartek J, et al. 2011. $53 \mathrm{BP} 1$ nuclear bodies form around DNA lesions generated by mitotic transmission of chromosomes under replication stress. Nature Cell Biology 13: 243-253.

Maciejowski J, Li YL, Bosco N, Campbell PJ, de Lange T. 2015. Chromothripsis and kataegis induced by telomere crisis. Cell 163: 1641-1654.

Martinez P, Blasco MA. 2015. Replicating through telomeres: A means to an end. Trends Biochem Sci 40: 504-515.

Martinez P, Thanasoula M, Munoz P, Liao CY, Tejera A, McNees C, Flores JM, Fernandez-Capetillo O, Tarsounas M, Blasco MA. 2009. Increased telomere fragility and fusions resulting from TRF1 deficiency lead to degenerative pathologies and increased cancer in mice. Genes Dev 23: 2060-2075.

McClintock B. 1938. The production of homozygous deficient tissues with mutant characteristics by means of the aberrant mitotic behavior of ring-shaped chromosomes. Genetics 23: 315-376.

McClintock B. 1942. The fusion of broken ends of chromosomes following nuclear fusion. Proc Natl Acad Sci 28: 458-463.

Meetei AR, Sechi S, Wallisch M, Yang DF, Young MK, Joenje H, Hoatlin ME, Wang WD. 2003. A multiprotein nuclear complex connects Fanconi anemia and Bloom syndrome. Mol Cell Biol 23: $3417-3426$.

Minocherhomji S, Ying SM, Bjerregaard VA, Bursomanno S, Aleliunaite A, Wu W, Mankouri HW, Shen HH, Liu Y, Hickson ID. 2015. Replication stress activates DNA repair synthesis in mitosis. Nature 528: 286-290.

Moreno A, Carrington JT, Albergante L, Al Mamun M, Haagensen EJ, Komseli ES, Gorgoulis VG, Newman TJ, Blow JJ. 2016. Unreplicated DNA remaining from unperturbed S phases passes through mitosis for resolution in daughter cells. Proc Natl Acad Sci 113: E5757-E5764.

Naim V, Rosselli F. 2009. The FANC pathway and BLM collaborate during mitosis to prevent micro-nucleation and chromosome abnormalities. Nat Cell Biol 11: 761-768.

Nasmyth K. 2011. Cohesin: A catenase with separate entry and exit gates? Nat Cell Biol 13: 1170-1177.

Nera B, Huang HS, Lai T, Xu L. 2015. Elevated levels of TRF2 induce telomeric ultrafine anaphase bridges and rapid telomere deletions. Nat Commun 6: 10132.

Neuman KC, Nagy A. 2008. Single-molecule force spectroscopy: Optical tweezers, magnetic tweezers and atomic force microscopy. Nat Methods 5: 491-505.

Nielsen CF, Hickson ID. 2016. PICH promotes mitotic chromosome segregation: Identification of a novel role in rDNA disjunction. Cell Cycle 15: 2704-2711.

Nielsen CF, Huttner D, Bizard AH, Hirano S, Li TN, PalmaiPallag T, Bjerregaard VA, Liu Y, Nigg EA, Wang LHC, et al. 2015. PICH promotes sister chromatid disjunction and cooperates with topoisomerase II in mitosis. Nat Commun 6: 8962.

Palm W, de Lange T. 2008. How shelterin protects mammalian telomeres. Annu Rev Genet 42: 301-334.

Pedersen RT, Kruse T, Nilsson J, Oestergaard VH, Lisby M. 2015. TopBP1 is required at mitosis to reduce transmission of DNA damage to G1 daughter cells. J Cell Biol 210: 565-582.

Piskadlo E, Tavares A, Oliveira RA. 2017. Metaphase chromosome structure is dynamically maintained by condensin I-directed DNA (de)catenation. Elife 6: 1328.

Pitchai GP, Kaulich M, Bizard AH, Mesa P, Yao Q, Sarlos K, Streicher W, Nigg E, Montoya G, Hickson I. 2017. A novel TPR-BEN domain interaction mediates PICH-BEND3 association. Nucleic Acids Res (in press).

Porter AC, Farr CJ. 2004. Topoisomerase II: Untangling its contribution at the centromere. Chromosome Res 12: 569-583.

Raynard S, Bussen W, Sung P. 2006. A double Holliday junction dissolvasome comprising BLM, topoisomerase III $\alpha$, and BLAP75. J Biol Chem 281: 13861-13864.

Rosin MP, German J. 1985. Evidence for chromosome instability in vivo in Bloom syndrome: Increased numbers of micronuclei in exfoliated cells. Hum Genet 71: 187-191.

Rouzeau S, Cordelieres FP, Buhagiar-Labarchede G, Hurbain I, Onclercq-Delic R, Gemble S, Magnaghi-Jaulin L, Jaulin C, Amor-Gueret M. 2012. Bloom's syndrome and PICH helicases cooperate with topoisomerase II $\alpha$ in centromere disjunction before anaphase. PLoS One 7: e33905.

Sarbajna S, Davies D, West SC. 2014. Roles of SLX1-SLX4, MUS81-EME1, and GEN1 in avoiding genome instability and mitotic catastrophe. Genes Dev 28: 1124-1136.

Schoeffler AJ, Berger JM. 2008. DNA topoisomerases: Harnessing and constraining energy to govern chromosome topology. $Q$ Rev Biophys 41: 41-101.

Schvartzman JB, Stasiak A. 2004. A topological view of the replicon. EMBO Rep 5: 256-261. 
Sfeir A, Kosiyatrakul ST, Hockemeyer D, MacRae SL, Karlseder J, Schildkraut CL, de Lange T. 2009. Mammalian telomeres resemble fragile sites and require TRF1 for efficient replication. Cell 138: 90-103.

Sims AE, Spiteri E, Sims RJ III, Arita AG, Lach FP, Landers T, Wurm M, Freund M, Neveling K, Hanenberg H, et al. 2007. FANCI is a second monoubiquitinated member of the Fanconi anemia pathway. Nat Struct Mol Biol 14: 564-567.

Singh TR, Ali AM, Busygina V, Raynard S, Fan Q, Du CH, Andreassen PR, Sung P, Meetei AR. 2008. BLAP18/RMI2, a novel OB-fold-containing protein, is an essential component of the Bloom helicase-double Holliday junction dissolvasome. Genes Dev 22: 2856-2868.

Singleton MR, Dillingham MS, Wigley DB. 2007. Structure and mechanism of helicases and nucleic acid translocases. Annu Rev Biochem 76: 23-50.

Sirri V, Roussel P, Hernandez-Verdun D. 1999. The mitotically phosphorylated form of the transcription termination factor TTF-1 is associated with the repressed rDNA transcription machinery. J Cell Sci 112 (Pt 19): 3259-3268.

Smogorzewska A, Matsuoka S, Vinciguerra P, McDonald ER, Hurov KE, Luo J, Ballif BA, Gygi SP, Hofmann K, D'Andrea $\mathrm{AD}$, et al. 2007. Identification of the FANCI protein, a monoubiquitinated FANCD2 paralog required for DNA repair. Cell 129: 289-301.

Stark WM, Sherratt DJ, Boocock MR. 1989. Site-specific recombination by $\mathrm{Tn} 3$ resolvase: Topological changes in the forward and reverse reactions. Cell 58: 779-790.

Sullivan M, Higuchi T, Katis VL, Uhlmann F. 2004. Cdc14 phosphatase induces rDNA condensation and resolves cohesin-independent cohesion during budding yeast anaphase. Cell 117: $471-482$.

Sun H, Karow JK, Hickson ID, Maizels N. 1998. The Bloom's syndrome helicase unwinds G4 DNA. J Biol Chem 273: 27587-27592.

Suski C, Marians KJ. 2008. Resolution of converging replication forks by RecQ and topoisomerase III. Mol Cell 30: 779-789.

Tanaka K, Hao Z, Kai M, Okayama H. 2001. Establishment and maintenance of sister chromatid cohesion in fission yeast by a unique mechanism. EMBO J 20: 5779-5790.

Thompson SL, Compton DA. 2011. Chromosomes and cancer cells. Chromosome Res 19: 433-444.

Uhlmann F, Wernic D, Poupart MA, Koonin EV, Nasmyth K. 2000. Cleavage of cohesin by the CD clan protease separin triggers anaphase in yeast. Cell 103: 375-386.

Vinciguerra P, Godinho SA, Parmar K, Pellman D, D’Andrea AD. 2010. Cytokinesis failure occurs in Fanconi anemia pathway-deficient murine and human bone marrow hematopoietic cells. J Clin Invest 120: 3834-3842.

Voit R, Seiler J, Grummt I. 2015. Cooperative action of Cdk1/ cyclin B and SIRT1 is required for mitotic repression of rRNA synthesis. PLoS Genet 11: e1005246.

Vos SM, Tretter EM, Schmidt BH, Berger JM. 2011. All tangled up: How cells direct, manage and exploit topoisomerase function. Nat Rev Mol Cell Biol 12: 827-841.

Wallis JW, Chrebet G, Brodsky G, Rolfe M, Rothstein R. 1989. A hyper-recombination mutation in $S$. cerevisiae identifies a novel eukaryotic topoisomerase. Cell 58: 409-419.

Wang BD, Yong-Gonzalez V, Strunnikov AV. 2004. Cdc14p/ FEAR pathway controls segregation of nucleolus in S. cerevisiae by facilitating condensin targeting to rDNA chromatin in anaphase. Cell Cycle 3: 960-967.
Wang LHC, Schwarzbraun T, Speicher MR, Nigg EA. 2008. Persistence of DNA threads in human anaphase cells suggests late completion of sister chromatid decatenation. Chromosoma 117: 123-135.

Wang F, Yang YT, Singh TR, Busygina V, Guo R, Wan K, Wang WD, Sung P, Meetei AR, Lei M. 2010a. Crystal structures of RMI1 and RMI2, two OB-fold regulatory subunits of the BLM complex. Structure 18: 1159-1170.

Wang LHC, Mayer B, Stemmann O, Nigg EA. 2010b. Centromere DNA decatenation depends on cohesin removal and is required for mammalian cell division. $J$ Cell Sci 123: 806-813.

Wang JD, Chen JJ, Gong ZH. 2013. TopBP1 controls BLM protein level to maintain genome stability. Mol Cell 52: 667-678.

Wold MS. 1997. Replication protein A: A heterotrimeric, singlestranded DNA-binding protein required for eukaryotic DNA metabolism. Апnu Rev Biochem 66: 61-92.

Wu L, Hickson ID. 2003. The Bloom's syndrome helicase suppresses crossing over during homologous recombination. $\mathrm{Na}$ ture 426: 870-874.

Wu L, Davies SL, North PS, Goulaouic H, Riou JF, Turley H, Gatter KC, Hickson ID. 2000. The Bloom's syndrome gene product interacts with topoisomerase III. J Biol Chem 275: 9636-9644.

Wu L, Davies SL, Levitt NC, Hickson ID. 2001. Potential role for the BLM helicase in recombinational repair via a conserved interaction with RAD51. J Biol Chem 276: 19375-19381.

Wu L, Bachrati CZ, Ou J, Xu C, Yin J, Chang M, Wang W, Li L, Brown GW, Hickson ID. 2006. BLAP75/RMI1 promotes the BLM-dependent dissolution of homologous recombination intermediates. Proc Natl Acad Sci 103: 4068-4073.

Wuite GJL, Smith SB, Young M, Keller D, Bustamante C. 2000. Single-molecule studies of the effect of template tension on T7 DNA polymerase activity. Nature 404: 103-106.

Xu DY, Guo R, Sobeck A, Bachrati CZ, Yang J, Enomoto T, Brown GW, Hoatlin ME, Hickson ID, Wang WD. 2008. RMI, a new OB-fold complex essential for Bloom syndrome protein to maintain genome stability. Genes Dev 22: 2843 2855.

Xu D, Muniandy P, Leo E, Yin J, Thangavel S, Shen X, Ii M, Agama K, Guo R, Fox D III, et al. 2010. Rifl provides a new DNA-binding interface for the Bloom syndrome complex to maintain normal replication. EMBO J 29: 3140-3155.

Xue XY, Raynard S, Busygina V, Singh AK, Sung P. 2013. Role of replication protein A in double Holliday junction dissolution mediated by the BLM-Topo III $\alpha-$ RMI1-RMI2 protein complex. J Biol Chem 288: 14221-14227.

Yin JH, Sobeck A, Xu C, Meetei AR, Hoatlin M, Li L, Wang WD. 2005. BLAP75, an essential component of Bloom's syndrome protein complexes that maintain genome integrity. EMBO J 24: 1465-1476.

Ying SM, Minocherhomji S, Chan KL, Palmai-Pallag T, Chu WK, Wass T, Mankouri HW, Liu Y, Hickson ID. 2013. MUS81 promotes common fragile site expression. Nat Cell Biol 15: 1001-1007.

Zhang CZ, Spektor A, Cornils H, Francis JM, Jackson EK, Liu SW, Meyerson M, Pellman D. 2015. Chromothripsis from DNA damage in micronuclei. Nature 522: 179-184.

Zou Y, Liu YY, Wu XM, Shell SM. 2006. Functions of human replication protein A (RPA): From DNA replication to DNA damage and stress responses. J Cell Physiol 208: 267-273. 


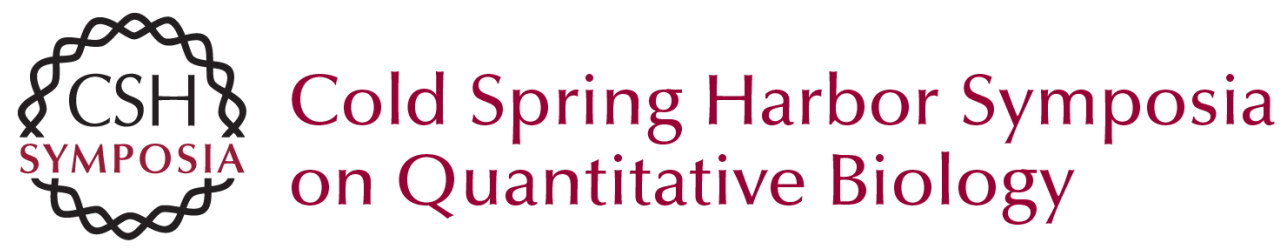

\section{Knotty Problems during Mitosis: Mechanistic Insight into the Processing of Ultrafine DNA Bridges in Anaphase}

Kata Sarlós, Andreas Biebricher, Erwin J.G. Petermann, et al.

Cold Spring Harb Symp Quant Biol 2017 82: 187-195 originally published online November 22, 2017

Access the most recent version at doi:10.1101/sqb.2017.82.033647

References This article cites 119 articles, 38 of which can be accessed free at: http://symposium.cshlp.org/content/82/187.full.html\#ref-list-1

Creative This article is distributed under the terms of the

Commons http://creativecommons.org/licenses/by-nc/4.0/, which permits reuse and

License redistribution, except for commercial purposes, provided that the original author and source are credited.

Email Alerting

Receive free email alerts when new articles cite this article - sign up in Service the box at the top right corner of the article or click here. 